\title{
FUNÇÕES ATENCIONAIS DE CRIANÇAS COM ANOMALIAS CRANIOFACIAIS: UM ESTUDO SOBRE A CONCEPÇÃO DE PROFESSORES
}

Jhenifer Prescilla Dias ${ }^{1}$, Roberta Aparecida Zotto ${ }^{2}$, Ana Vera Niquerito Bozza ${ }^{3}$, Maria de Lourdes Merighi Tabaquim $^{4}$

${ }^{1}$ Mestranda do Programa de Pós-Graduação em Psicologia do Desenvolvimento e Aprendizagem da Universidade Estadual Paulista - UNESP, Bauru, SP. Psicóloga Educacional.

${ }^{2}$ Graduação em Psicologia pelas Faculdades Integradas de Jaú - FIJ. Pós-graduanda em Reabilitação Neuropsicológica pela Universidade Federal de São Carlos - UFSCAR, São Carlos, SP. Psicóloga Clínica.

${ }^{3}$ Doutora pelo Programa de Pós-Graduação em Ciências da Reabilitação pelo Hospital de Reabilitação de Anomalias Craniofaciais da USP - HRAC, Bauru, SP. Docente nas graduações em Psicologia e Pedagogia das Faculdades Integradas de Jaú - FIJ.

${ }^{4}$ Doutora em Ciências Médicas pela Universidade Estadual de Campinas - UNICAMP, Campinas, SP. Docente do Departamento de Fonoaudiologia da Faculdade de Odontologia de Bauru da USP e do Programa de Pós-Graduação em Ciências da Reabilitação do Hospital de Reabilitação de Anomalias Craniofaciais da USP - HRAC, Bauru, SP. Coordenadora do Laboratório de Neuropsicologia do Desenvolvimento, Fissuras e Anomalias Craniofaciais HRAC/USP.

\section{RESUMO}

Compreender os pressupostos teóricos das anomalias craniofaciais e as implicações cognitivas da função atencional é essencial para que o professor, como mediador do processo educativo, compreenda seu aluno desatento com fissura labiopalatina, sindrômico ou não, e desenvolva estratégias de manejo em sala de aula. Este estudo caracterizou a concepção de professores sobre a função atencional, condições atípicas craniofaciais e o emprego de estratégias educativas relacionadas. Participaram 129 professores de ensino fundamental que responderam a um protocolo de investigação com questões sobre conceitos, características e estratégicas de intervenção. Os dados indicaram que $54 \%$ desconheciam as noções básicas sobre as temáticas, evidenciando repertórios limitados no trato ao aluno com anomalias craniofaciais e no emprego de estratégias efetivas de manejo atencional em sala de aula. Os resultados apontaram para a necessidade da adoção de programas de treinamento de competências e a difusão de conhecimento, como também, sinalizaram a importância de se rever as políticas públicas existentes no processo de formação de professores do ensino básico, essencial na capacitação por excelência, de profissionais da Educação.

Palavras-chave: Neuropsicologia. Atenção. Professor. Fissura Palatina. Síndrome.

\section{THE ATTENTIONAL FUNCTIONS OF CHILDREN WITH CRANIOFACIAL ANOMALIES: A STUDY ON THE CONCEPTION OF TEACHERS}

\begin{abstract}
Understanding the theoretical assumptions of craniofacial anomalies and the cognitive implications of the attentional function is essential for the teacher, as mediator of the educational process, to understand his inattentive student with cleft lip and palate, syndromic or not, and develop management strategies in the classroom. This study characterized the conception of teachers about the attentional function, atypical craniofacial conditions and the use of related educational strategies. A total of 129 primary school teachers participated in a research protocol with questions about intervention concepts, characteristics and strategies. The data indicated that $54 \%$ did not know the basics about the subjects, showing limited repertoires in the treatment of the student with craniofacial anomalies and in the use of effective strategies of attention management in the classroom. The results pointed to the need to adopt competency training programs and the dissemination of knowledge, as well as the importance of reviewing existing public policies in the process of training primary school teachers, essential in the training of excellence, professionals.
\end{abstract}

Keywords: Neuropsychology. Attention. Teacher. Cleft palate. Syndrome. 


\section{FUNCIONES ATENCIONALES DE NIÑOS CON ANOMALIAS CRANEFACIALES: UN ESTUDIO SOBRE LA CONCEPCIÓN DE PROFESORES}

\section{RESUMEN}

La comprensión de los supuestos teóricos de las anomalías craneofaciales y las implicaciones cognitivas de la función atencional es esencial para que el profesor, como mediador del proceso educativo, comprenda a su alumno desatento con fisura labiopalatina, sindrómico o no, y desarrolle estrategias de manejo en el aula. Este estudio caracterizó la concepción de profesores sobre la función atencional, condiciones atípicas craneofaciales y el empleo de estrategias educativas relacionadas. Participaron 129 profesores de enseñanza fundamental que respondieron a un protocolo de investigación con cuestiones sobre conceptos, características y estrategias de intervención. Los datos indicaron que el $54 \%$ desconocía las nociones básicas sobre las temáticas, evidenciando repertorios limitados en el trato al alumno con anomalías craneofaciales y en el empleo de estrategias efectivas de manejo atencional en el aula. Los resultados apuntaron a la necesidad de la adopción de programas de entrenamiento de competencias y la difusión de conocimiento, como también, señaló la importancia de revisar las políticas públicas existentes en el proceso de formación de profesores de la enseñanza básica, esencial en la capacitación por excelencia, profesionales de la educación.

Palabras clave: Neuropsicología. Atención. Maestro. Fissura Palatina. Síndrome.

\section{INTRODUÇÃO}

O cérebro humano pode ser caracterizado por um complexo conjunto de sistemas que se interconectam e colaboram entre si para um funcionamento harmônico e equilibrado. Apesar de cada um deles ter uma especificidade e independência funcional da rede neuronal e comportamental do indivíduo, o funcionamento anormal de qualquer estrutura poderá afetar todas as demais estruturas cerebrais, afetando não somente a função específica da área comprometida (LURIA, 1981; POPI; RIECHI, 2017).

O processo de crescimento está extremamente relacionado com a maturação e o desenvolvimento humano, no qual ocorrem continuamente durante todo o ciclo de vida (RÉ, 2011). O desenvolvimento humano pode ser caracterizado por três fases no período pré-natal: germinal, embrionária e fetal. Durante essas fases de gestação: "o zigoto original unicelular transforma-se em um embrião e depois em um feto" (PAPALIA; OLDS; FELDMAN, 2006, p.64). Tanto antes como depois do nascimento, o desenvolvimento segue dois princípios fundamentais: céfalocaudal e próximo-distal. Ambos com origem do latim, significam "da cabeça para a cauda" e "do próximo ao distante" respectivamente, determinando que 0 desenvolvimento ocorre da cabeça para a parte inferior do tronco e das partes próximas (centro do corpo) para as partes externas. A cabeça e o tronco do embrião desenvolvem-se antes dos membros, e braços e pernas antes dos dedos de pés e mãos.

Os aspectos físicos, ambientais e emocionais da mãe têm um efeito profundo sobre o desenvolvimento do cérebro do feto, pois durante a gravidez, o cérebro é vulnerável a doenças que podem causar a morte ou deficiências físicas ou cognitivas. À medida que o feto cresce, podem ocorrer anormalidades, sejam ao nível celular ou mesmo disfuncionais, que levam a transtornos mentais (PAPALIA; OLD; FELDMAN, 2006; BEE; BOYD, 2011). O crescimento do cérebro no período anterior e posterior ao nascimento é fundamental para todo o processo de desenvolvimento, levando em consideração os âmbitos físico, cognitivo e emocional do indivíduo (PAPALIA; OLD; FELDMAN, 2006). A progressiva aquisição das habilidades é considerada uma tarefa essencial para o resultado de ações simultâneas de fatores genéticos e ambientais dotados de plasticidade, que se modificam mutuamente.

Para que ocorra o processo de aprendizagem, Ladewig (2000) explica que o indivíduo passa por estágios caracterizados por diversas mudanças, entre elas encontra-se o processo da atenção, que se inicia no momento de exposição da primeira vez da atividade até o instante em que já foi desenvolvida uma habilidade para tal realização, sem necessidade de muito esforço cognitivo. Os estudos sobre o 
desenvolvimento da atenção expandiram-se com os trabalhos sobre percepção visual em bebês. Estes estudos têm-se apoiado atualmente em técnicas indiretas para explorar aspectos cognitivos dos bebês, como, medidas eletrofisiológicas, respostas por habituação, preferências no olhar, na busca, no degustar, no cheirar e ainda no condicionamento clássico e operante (LEWIS, 1995).

A atenção é um pré-requisito para favorecer a memorização de determinada informação, generalizar o conceito e adquirir o conhecimento necessário para a sobrevivência física, cognitiva e psicossocial no processo de aprendizagem (BEE; BOYD, 2011; OLIVER; ANTONIUK; BRUCK, 2017) e pode ser concebida como uma função neuropsicológica complexa e multifacetada, cujo papel é desempenhar aquilo que o ser percebe, lembra, pensa, sente e faz. Com isso, essa função não pode ser considerada uma atividade isolada do cérebro, uma vez que funciona de forma conjunta com outras funções cognitivas, sendo integrada às funções executivas cerebrais, que se dividem em seis grupos: ativação, foco, esforço, emoção, memória, monitoramento e autorregulação das ações. A ativação estaria relacionada a organização; o foco seria a sustentação e desvio da atenção às tarefas; o esforço vinculado a regulação do estado de alerta, a velocidade de processamento da informação, além do esforço sustentado. Já a emoção está vinculada a administração das frustações e aos moldes das emoções, e por fim, o monitoramento e autoregulação das ações do indivíduo (BROWN, 2007).

\section{Fissuras Labiopalatinas e suas implicações no processo educativo}

De acordo com Gannam, Teixeira e Tabaquim (2015) a fissura labiopalatina (FLP) é um dos defeitos congênitos mais comuns que atingem a face do ser humano, cuja ocorrência está relacionada com alterações na fusão dos processos faciais embrionários. Essa fissura tratase de uma anomalia craniofacial decorrente de uma interrupção, parcial ou total, na continuidade dos tecidos do palato e/ou do lábio. A etiologia das fissuras labiopalatinas é definida como multifatorial, incluindo fatores genéticos e ambientais (TRINDADE; SILVA FILHO, 2007; AQUINO et al., 2011).

Em relação aos fatores ambientais, Tovani-Palone e Saldias-Vargas (2016) incluem elementos como a dieta maternal, suplementação vitamínica, álcool, fumo e uso de drogas anticonvulsivantes na gestação. Entre os fatores genéticos, os autores destacam diferentes genes relacionados à formação craniofacial, como TGF-b3 (Transforming growth factor beta 3), MSX1 (Msh homeobox 1), IRF6 (Interferon regulatory factor 6), FGFs (Fibroblast growth factor), PVRL1 (Poliovirus receptor related-1), FOXE1 (forkhead box E1), JAG2 (Jagged 2) e TBX22 (T-box 22).

Os dados disponíveis na literatura sugerem que no Brasil, a prevalência de fissuras labiopalatinas acomete cerca de um indivíduo em cada 650 nascidos vivos (NAGEM; MORAES; ROCHA, 1968; CAPELOZZA FILHO; SILVA FILHO, 1994; AQUINO et al., 2011). Segundo Trindade e Silva Filho (2007) a maior prevalência em média é entre 1 e 2 indivíduos brancos para cada 1000 nascimentos.

Segundo Ferro, Moretti e Tabaquim (2013) indivíduos com fissuras labiopalatinas podem apresentar síndromes relacionadas a esta condição de má formação. As síndromes podem ser definidas como um conjunto de sinais ou sintomas provocados pelo mesmo organismo e dependentes de causas diversas, sendo definidas por um conjunto de características do ser humano. A criança sindrômica pode apresentar alterações cognitivas, próprias da sua condição, e ter associado a essas limitações alguns problemas de comportamento, o que leva ao agravamento da sua produtividade e adaptação no contexto escolar. Desta forma, a caracterização dos sinais e sintomas fonoaudiológicos, como também a busca do diagnóstico etiológico e a constatação que acometem 0 indivíduo com fissura labiopalatina atualmente tem sido uma das preocupações dos profissionais da área de saúde (MONDELLI; VENTURA; FENIMAN, 2013).

Ademais, a literatura tem apontado alterações significativas nas habilidades comunicativas de crianças com Fissura Labiopalatina e prejuízos nas competências necessárias ao desempenho escolar satisfatório, tais como: às funções cognitivas-linguísticas semânticas e pragmáticas expressivas, a memória de trabalho auditiva e do domínio acústico-motriz de estrutura rítmica, e funções executivas, entre essas, as atencionais, possuindo maior risco para o desenvolvimento de déficits de linguagem (JACOB; TABAQUIM, 2014; PRUDENCIATTI; PEREIRA; TABAQUIM, 2016). Para Tovani-Palone (2015) os distúrbios na fala, mais especificamente na articulação dos sons da fala, acarretam 
alterações que podem interferir na interação do indivíduo em seu meio. A população com fissura labiopalatina pode ser vista como um campo de estudos dos distúrbios da comunicação, em decorrência das alterações estruturais e funcionais inerentes à fissura. Essas alterações interferem no processo de comunicação, ocasionando prejuízos nas interações sociais e na aprendizagem, bem como, no desenvolvimento de competências cognitivas e afetivas, necessitando de esforços individuais dinâmicos, cognitivos e comportamentais, no qual, se modificam constantemente para o manejo das demandas internas e/ou externas e a adaptação ao contexto psicossocial (JOAQUIM; TABAQUIM, 2013).

Sabe-se que a linguagem, assim como a atenção, é uma ferramenta essencial para o desenvolvimento da aprendizagem, além das condições orgânicas e psíquicas do indivíduo. Levando em consideração o ponto de vista neuropsicológico: "A linguagem constitui uma forma complexa de comportamento que exige a integridade de zonas cerebrais, fundamentais para a sua aquisição e desenvolvimento" (LURIA, 1966; OULETTE, 2014 apud PRUDENCIATTI; PEREIRA; TABAQUIM, 2016, p.263).

No entanto, Holanda e Collet (2012) postulam que nesses casos considera-se extremamente necessário a elaboração de estratégias de inclusão que busquem viabilizar arranjos diferenciados para os serviços de saúde, no qual, sejam voltados para a integralidade do cuidado, facilitando o aumento da autonomia dos indivíduos, sendo necessária a construção de uma lógica diferenciada de atenção. A angústia gerada de não conseguir compreender os outros e de não conseguir se expressar, resulta na repressão da criatividade e na capacidade de aprender, gerando um autoconceito destrutivo, sentimentos de inferioridade, ocasionando desajuste psicossocial e até atrasos cognitivos (JOAQUIM; TABAQUIM, 2013). Porém, as relações escolares podem ser vistas como uma rede social significativa na vida destas crianças. É possível que ocorram certas dificuldades da criança com anomalia no estabelecimento de contato em seu meio, pelo fato das crianças com esta má formação congênita desde o início da vida escolar, vivenciarem o preconceito devido à presença da fissura labiopalatina e seus comprometimentos relacionados principalmente a aparência física. Entretanto, há a possibilidade de serem firmados bons contatos, se estas crianças forem aceitas nos grupos (CAMINHA, 2008; SILVA et al., 2013).

Neste contexto, a atuação do professor é extremamente importante, devido às inadequações e dificuldades com relação à matéria e questões relacionadas ao comportamento. $\mathrm{O}$ professor perante a classe conquista a autoridade quando ele tem informações sobre a realidade de seus alunos, compreendendo-os e respeitando-os, com objetivo de maior facilidade de manuseio profissional com estes alunos, além de dominar o conteúdo e saber adaptar as estratégias de forma eficiente para ensiná-los em sua especificidade (FERRO; MORETTI; TABAQUIM, 2013; NIQUERITO; TABAQUIM, 2013).

A realização da presente pesquisa justifica-se pela importância de estudos relacionados à essa prática da Psicologia, tendo em vista o trabalho conjunto com o professor no processo ensino-aprendizagem, considerando a quantidade significativa de alunos com transtornos de atenção e anomalias craniofaciais e as escassas informações sobre essa temática. Identificam-se dificuldades na compreensão sobre o neurodesenvolvimento das competências necessárias para o sucesso escolar.

Considerando o papel e a influência do professor no processo de aprendizagem, é extremamente importante que o mesmo saiba identificar de imediato as dificuldades relacionadas à atenção e a comunicação, além de saber atuar como mediador nesses casos. Ressalta-se que, o diagnóstico precoce de tais comprometimentos e dificuldades, tem como consequência um prognóstico positivo, facilitando a adaptação do aluno e garantindo uma educação específica e de qualidade. Diante disso, este estudo teve como objetivo caracterizar o nível de informação do professor sobre a função atencional e anomalias craniofaciais, bem como o uso de estratégias educativas com a população alvo.

\section{MÉTODO}

O projeto atendeu aos procedimentos éticos da pesquisa (aprovação CEP no 1.796.316), com a adoção dos termos de consentimento obrigatórios ao participante voluntário, conforme resolução do Conselho Nacional de Saúde CNS 466/2012. 


\section{Amostra}

A população alvo do estudo foi composta por 129 professores do ensino fundamental regular ou especializado, de escolas públicas e privadas, na faixa etária de 21 a 65 anos (média de 42,7 anos) e desvio padrão $(11,0)$, de ambos os sexos, sendo a maioria do sexo feminino $(n=76)$, residentes em diferentes cidades do interior do estado de São Paulo. Utilizou-se como critério de inclusão: concordância formal com a participação na pesquisa; atuar como professor do ensino fundamental (primeiro ciclo) e ter acesso ao computador e sistema online de internet. Como critério de exclusão foi considerado: não ter a graduação em Pedagogia e a retirada do consentimento pós-informado.

\section{MATERIAL}

Os professores das escolas participantes responderam ao Questionário de Identificação e ao Protocolo de Investigação da Informação sobre atenção, anomalias craniofaciais $e$ síndromes relacionadas, elaborado para este estudo. Por meio do Questionário de Identificação buscaram-se os dados sociodemográficos da amostra relacionados ao gênero, idade, escolaridade, tempo de formação profissional, tempo de atuação, tempo de atuação na mesma escola, ano escolar que leciona e formação complementar.

O Protocolo de Investigação da Informação sobre atenção, anomalias craniofaciais e síndromes relacionadas contou com 13 questões objetivas, de múltipla escolha, sobre as seguintes temáticas: níveis de atenção infantil, anomalias craniofaciais, fissura labiopalatina e estratégias de manejo do professor para a sala de aula.

\section{PROCEDIMENTOS}

Inicialmente foi realizado o convite às escolas elegidas por conveniência, para adesão à proposta de pesquisa. Após a concordância formal das instituições, realizou-se o convite aos professores. Posteriormente, foram aplicados os instrumentos construídos exclusivamente para este estudo.

Para a análise de dados, foi construído um banco de dados utilizando-se de um software específico à organização, elaboradas tabelas de distribuição de frequência para as variáveis categóricas, calculando-se a mediana e desviospadrão para as variáveis quantitativas. As tabelas de contingência foram preparadas para determinar a distribuição de frequência de acertos, de acordo com as variáveis independentes, utilizando-se o teste estatístico McNemar's Test para avaliar as frequências correlacionadas. Em todos os testes foi adotado um nível de significância de 5\%.

\section{RESULTADOS}

Os resultados apontaram que além da graduação em Pedagogia, fundamental para o exercício na docência básica, constatou-se outras formações de nível superior, sendo $46 \%$ em Educação Física, 38\% em Letras, $15 \%$ em Psicologia, Direito e Ciências Biológicas, e 7\% em Artes, Administração, Enfermagem, Odontologia e Ciências Contábeis. Da amostra, $72 \%$ possuíam pós-graduação Lato Sensu e $2 \%$ Stricto Sensu (mestrado), observando-se que $8 \%$ dos professores possuíam duas formações nesta modalidade. No entanto, verificou-se também que $18 \%$ dos participantes não contemplaram nenhuma formação em pós-graduação.

Identificou-se que a maioria dos participantes, correspondente a $22 \%$, atuava entre 5 e 10 anos na atividade docente, seguido de $20 \%$ atuantes até 4 anos. A minoria (4\%) foi composta de professores que possuíam mais de 30 anos de atuação, seguido de $8 \%$ de professores com 26 a 30 anos. Observou-se que os professores com menor tempo de exercício profissional realizaram mais cursos, na comparação de professores com maior tempo. Quanto à regência de aulas, muitos professores atuavam em mais de um nível de escolaridade, abrangendo um período integral, e 2,9\% acumulavam dois cargos exercidos em períodos diferentes, sendo que $30 \%$ atuavam na Educação Especial e $26 \%$ no segundo ano do Ensino Fundamental. A maioria dos professores, que correspondeu a $44,9 \%$, era atuante em escolas Municipais, 41,8\% em escolas Estaduais, 7,7\% em instituições particulares, 6,2 \% em instituições não governamentais (ONGS) e 2,3\% não atuavam.

A partir dos resultados do Protocolo de Investigação da Informação sobre atenção, anomalias craniofaciais e síndromes relacionadas, foi possível identificar que as questões que obtiveram os maiores índices de acertos foram: Q6 $(89,1 \%)$ e Q9 $(77,5 \%)$. Os menores percentis de acertos foram evidenciados nas questões $3(24 \%)$ e $4(25,6 \%)$, conforme apresentado na Figura 1. 
Figura 1. Representação do percentual de acertos por questão do Protocolo de Investigação da Informação Atencional (PIIA)

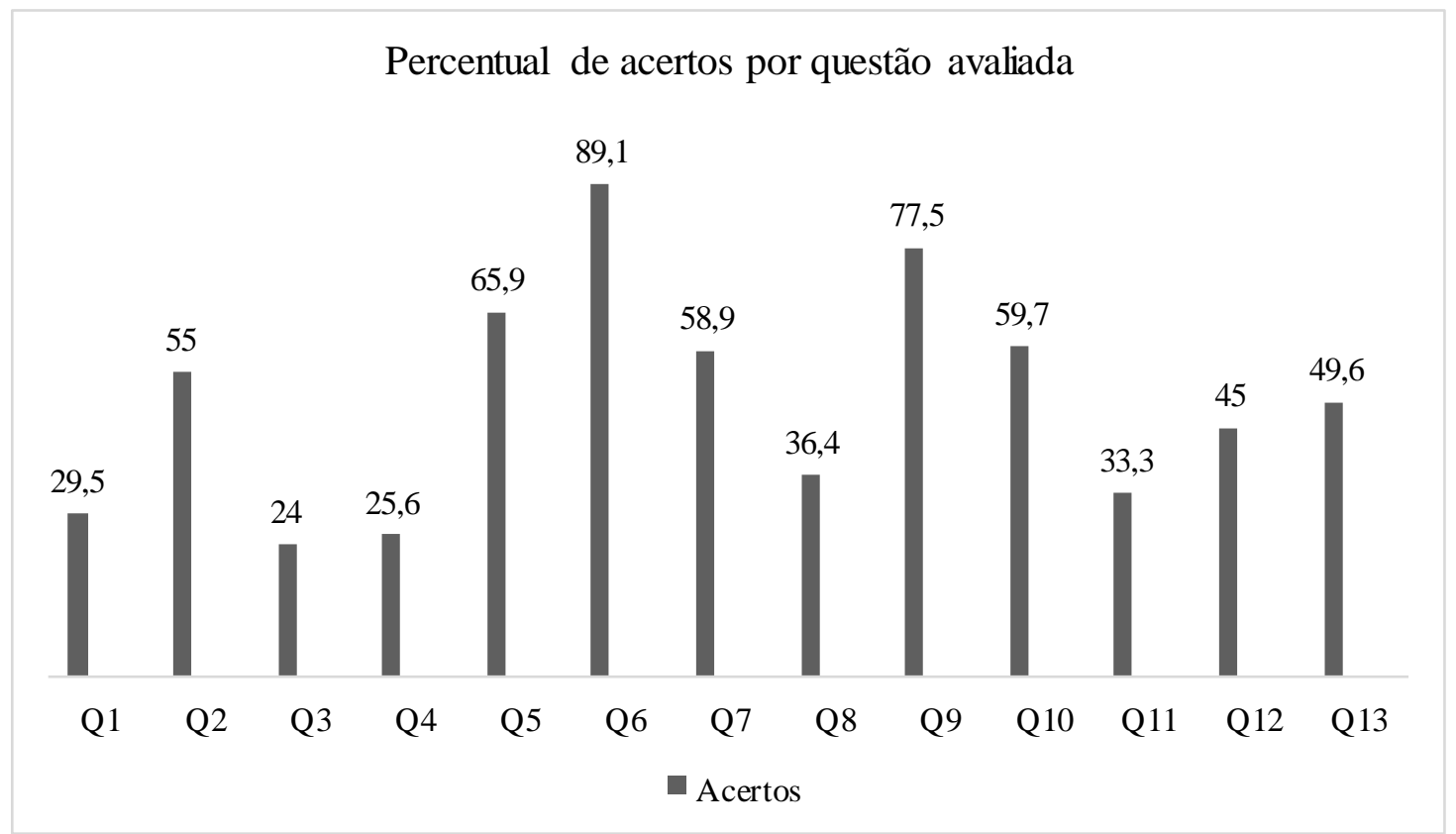

Fonte: Autoras (2017)

Foi analisada também, a porcentagem de acertos por temática, como pode ser visualizado na Figura 2. Verificou-se que a temática com maior percentual de acertos foi em relação às Estratégias de Intervenção Atencional (56\%).

Figura 2. Representação do percentual de acertos por temática do Protocolo de Investigação da Informação Atencional (PIIA)

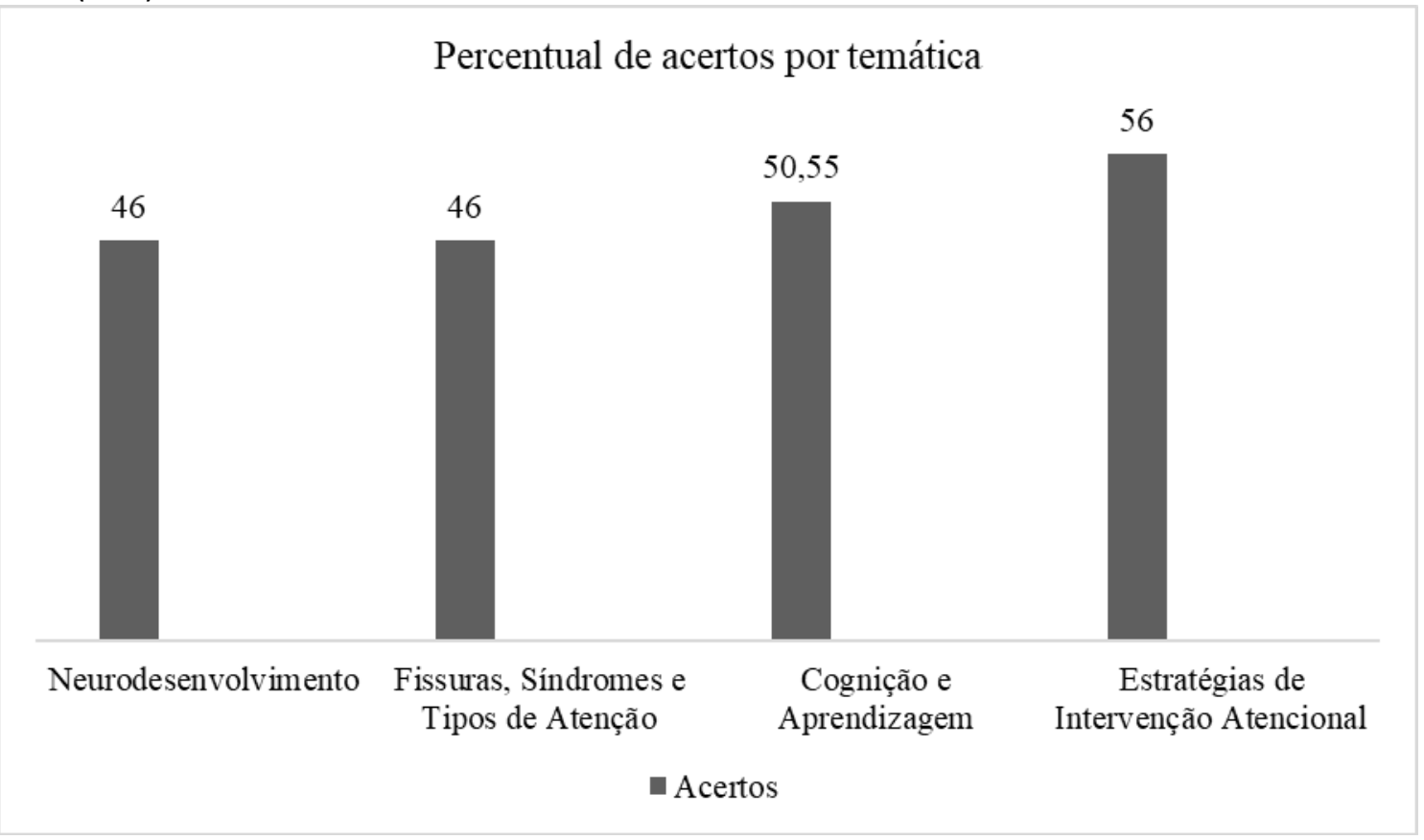

Fonte: Autoras (2017)

Pode ser observado que $46 \%$ ( $n=59)$ dos participantes possuem informação a respeito das noções básicas do neurodesenvolvimento (maturação cerebral, períodos do neurodesenvolvimento e conexões neuronais). Pelas questões 1,7 e 13, pode-se apontar o 
precário conhecimento a respeito de aspectos fundamentais anterior e posterior ao nascimento para todo o processo de desenvolvimento, levando em consideração os âmbitos físico, cognitivo e emocional do indivíduo, pois, a maturação do cérebro, considerável antes do nascimento (com a produção das células nervosas) e ao longo dos dois primeiros anos de vida (com o crescimento contínuo do volume do cérebro) constitui períodos de grande vulnerabilidade, sendo essa informação de extrema importância para atuar de modo assertivo no processo de aprendizagem.

Em relação ao sistema atencional e anomalias craniofaciais, foram elaboradas as questões 3 , 4 e 6 . Constatou-se que $46 \%$ ( $n=59)$ dos participantes tinham informação e foram assertivos. Estes dados sugerem que quase metade dos professores tem informação referente a estas noções, sugerindo-se que frente à demanda de crianças com necessidades educativas diferenciadas, o professor tem se apresentado incipiente às informações referente ao desenvolvimento atípico e de procedimentos interventivos, especialmente aquelas relacionadas aos alunos com anomalias craniofaciais, distúrbios e dificuldade de aprendizagem.

\section{DISCUSSÃO}

Com o processo de maturação, o cérebro se torna menos plástico, e assim vai diminuindo a sua capacidade de adquirir novas conexões e aprendizados. Segundo Kotulak (1997) há quatro fases principais do desenvolvimento estrutural do cérebro. A primeira fase ocorre durante o estágio fetal, pois, nos primeiros meses da vida fetal, bilhões de células são formadas. Metade delas morre e estímulos externos organizam algumas e eliminam outras para formar a estrutura básica do cérebro, ou seja, a estrutura que caracteriza e diferencia as crianças em meninos e meninas. A segunda fase se dá logo após o nascimento, quando surgem trilhões de conexões entre as células, que formam os "mapas mentais" do cérebro, responsáveis, entre outras coisas, pela visão, linguagem e audição. Na terceira fase, que vai dos quatro aos dez anos de idade, novos aprendizados reorganizam e reforçam as conexões entre as células do cérebro humano. Novas conexões são formadas à medida que novos conhecimentos são adquiridos. A quarta e última fase ocorre após os dez anos de idade, no qual ainda capaz de sofrer mudanças físicas, o cérebro aprende e memoriza informações no decorrer de toda a vida. Diante disso, o ensino escolar deve ser ministrado de forma precisa e planejada, organizada de acordo com a fase na qual o cérebro encontra-se nas melhores condições de criar novas redes neuronais estáveis para manter as referidas informações de forma parecida ao que ocorre com a linguagem: se praticada todos os dias, faz com que as redes neuronais sejam mais fortes e a atividade mais efetiva (PAPALIA; OLDS, FELDMAN, 2006; BEE; BOYD, 2011).

Luria (1981) afirma que as funções mentais são organizadas em sistemas integrados, nos quais pode ser observada a ação de três importantes unidades funcionais do cérebro, controladas pelas respectivas áreas anatômicas: manutenção do tônus psíquico (função coordenada pela formação reticular, áreas hipotalâmicas e tálamo); recebimento, elaboração e conservação das informações (funções controladas por áreas parietal, temporal e occipital do córtex cerebral) e a programação, regulação e verificação da atividade mental (funções coordenadas por áreas anteriores dos hemisférios cerebrais, relacionadas às regiões frontais).

O processo de entrada e saída das informações (input e output respectivamente) é realizado devido à presença de células do cérebro, também conhecidas por neurônios. Os neurônios recebem, analisam, coordenam e transmitem informações, ou seja, são células que desempenham o papel de conduzir os impulsos nervosos. Estas células especializadas são, portanto, as unidades básicas do sistema que processa as informações e estímulos no corpo humano (KOTULAK, 1997; PAPALIA; OLDS; FELDMAN, 2006; BEE; BOYD, 2011).

Para que ocorra a comunicação entre as células nervosas, ocorrem as conexões neuronais, que são chamadas de "sinapses". Estas sinapses decorrem de estímulos provenientes do meio interno e externo ao organismo. Por ter sérias implicações nas vidas de crianças e adolescentes, as conexões sinápticas possuem um papel muito importante no processo aprendizagem (KOTULAK, 1997).

Os achados neste estudo podem ser comparados com um estudo realizado por Seno (2010) com 52 educadores da Rede Municipal de Ensino que buscou avaliar o nível de informação dos professores a respeito do Transtorno e Déficit 
de Atenção e Hiperatividade (TDAH). Foi constatado que este transtorno ainda é um assunto desconhecido pela maioria dos professores, levando em consideração as causas, idade de manifestação, médico especialista, cura, tratamento e comorbidades, apesar de muitos lecionarem para esse público. Já as questões que envolviam a prática de sala de aula, cujas respostas podiam ser resgatadas por acontecimentos do dia-a-dia, foram corretamente assinaladas, demonstrando a sensibilidade do educador mesmo quando não houve a busca pelo assunto em específico. As estratégias sugeridas são pertinentes, apesar da maioria das vezes não serem aplicadas. Este estudo corrobora com os resultados desta pesquisa, pois, observou-se que o educador tem um incipiente conhecimento sobre este transtorno.

Para o entendimento dos aspectos cognitivos da aprendizagem (discriminação de estímulos, inteligência, aprendizagem acadêmica e funções executivas) foram elaboradas as questões 2, 8, 9 e 11, cuja média de acertos foi de $50,55(n=65)$. Nesta perspectiva, pode-se dizer que o contexto educacional brasileiro relacionado a formação acadêmica do aluno, suscita o questionamento sobre a formação do professor. A falha qualificação dos profissionais da educação para lidar com a diversidade dos alunos, bem como para o funcionamento de aquisição de aprendizagem tem se apresentado uma barreira para o êxito do processo de aprendizagem de alunos, tanto na escola regular quanto no ensino especial (GLAT; PLETSCH, 2010).

Em relação ao nível de informação a respeito das estratégias de intervenção (estimulação da atenção em sala de aula, o processo de mediação na relação professor-aluno e atividades para estimular a atenção em crianças atencional), as questões 5, 10 e 12, apresentando uma média de acertos de $56(n=72)$. Ou seja, observa-se que metade dos professores consegue adaptar as estratégias educativas de acordo com as necessidades encontradas na diversidade da sala de aula. É fundamental que o professor tenha um respaldo científico no manejo com os alunos, para o aumento do rendimento da classe, pelo fato destes alunos demandarem maior atenção do professor, e consequentemente prejudicarem os demais alunos (NIQUERITO; TABAQUIM, 2013). Sabe-se que o desempenho escolar se encontra interligado a diversos fatores, tais como: âmbito escolar, contexto familiar e o próprio aluno. Entretanto, questões relacionadas à dificuldade de aprendizado, encontram-se em interfaces de educadores, sociólogos, psicólogos e médicos (ARAÚJO, 2002).

0 professor ao desenvolver seu planejamento, deve aplicar um olhar diferenciado sobre o seu trabalho. Embora o papel da escola necessite ser repensada, para atender a cada especificidade, é necessária uma reflexão, começando pelo profissional, para atender cada um dentro da sua necessidade e assim, possibilitando o desenvolvimento do seu trabalho com êxito. Apesar de o educador estar preparado para trabalhar com a diversidade em sala de aula, o mesmo acaba tendo que adaptar-se a este meio, sem qualquer valorização ou capacitação especifica (SILVA; ARRUDA, 2014).

O conhecimento acerca do desempenho e funcionamento escolar de crianças com fissura labiopalatina pode fundamentar a realização de ações e intervenções dirigidas ao aluno, à escola e à família (DOMINGUES et al., 2011). Contudo, nesta temática, observou-se um incipiente conhecimento do educador, o qual pode ser considerado um fator de risco para o desempenho acadêmico destes escolares (CARVALHO; GRENITTE; CIASCA, 2007; DOMINGUES et al., 2011; TABAQUIM et al., 2016). Ademais, considerando que a atenção é um pré-requisito para favorecer o processo de aprendizagem (OLIVER; ANTONIUK; BRUCK, 2017) contatou-se que a maioria dos professores possui a mínima noção de seu funcionamento.

De acordo com Sant' Ana (2005) os estudos sobre a atuação pedagógica na educação inclusiva postulam que 0 sucesso das intervenções, estão relacionadas com a implementação de amplas mudanças nas práticas pedagógicas, com a adoção de novos conceitos e estratégias (educação cooperativa), como por exemplo: a adaptação ou reconstrução do currículo escolar, o uso de novas técnicas e recursos específicos para a clientela, o estabelecimento de novas formas de avaliação, estimulação da participação dos pais e da comunidade na realidade social e educacional. Além disso, ressaltam-se, em especial, as atitudes positivas frente à inclusão de crianças com necessidades especiais no ensino regular. Pode ser constatado que há um desconhecimento do professor, seja ele de escola pública ou particular quanto ao assunto, o que contribui na afirmativa dos resultados obtidos nesta pesquisa. Observouse que frente à demanda de crianças com 
necessidades educativas diferenciadas, o professor tem se apresentado com baixo nível de informação a respeito do desenvolvimento atípico e de procedimentos interventivos, especialmente em relação aos alunos com anomalias craniofaciais (DOMINGUES et al., 2011; CIASCA; RODRIGUES; SALGADO, 2010; TABAQUIM et al., 2016). Destacase a importância da inclusão de temas relacionados à fissura labiopalatina em cursos de formação na área da saúde, tanto em nível da graduação quanto de pós-graduação. Segundo Tovani-Palone, Formenton e Bertolini (2018), a formação profissional voltada a essa temática é restrita no Brasil, possivelmente justificada pelo fato de somente o Hospital de Reabilitação de Anomalias Craniofaciais da Universidade de São Paulo (HRAC/USP) oferecer cursos de pósgraduação em níveis lato e stricto senso, nessa linha de pesquisa. O HRAC/USP é reconhecido como o maior centro de diagnóstico e tratamento em anomalias craniofaciais na América do Sul e referência mundial nesta especialidade, realizando todo tipo de cuidado cirúrgico e ambulatorial, multidisciplinar, para a plena reabilitação do paciente.

Ressalta-se também a importância em incorporar temas sobre as fissuras labiopalatinas e síndromes associadas, nos currículos dos cursos superiores, como os de graduação em saúde, bem como, na formação para profissionais do Sistema Único de Saúde (SUS). Tais medidas possibilitariam a ampliação e a descentralização da prestação de serviços a essa população, contribuindo para a melhoria da qualidade de vida dos pacientes e seus familiares, como também, na redução de encargos, de modo geral.

\section{CONSIDERAÇÕES FINAIS}

Mediante a realização deste estudo, foi constatado que referente ao nível de informação do professor sobre a função atencional e anomalias craniofaciais, $46 \%$ dos professores possuem conhecimento prévio sobre a temática investigada, o que demonstra despreparo para lidar com as adversidades em sala de aula. A maioria, que corresponde a $56 \%$ dos participantes apresentou maior conhecimento nas estratégias de intervenção, se comparados às demais temáticas relacionadas ao neurodesenvolvimento (46\%), as fissuras labiopalatinas, síndromes e função atencional (46\%) e aos aspectos cognitivos da aprendizagem $(50,55 \%)$. O desconhecimento sobre as temáticas sugere intervenções em sala de aula pouco efetivas e, muitas vezes, inadequadas, ocasionando a desmotivação e baixo aproveitamento escolar dos alunos desatentos e/ou com anomalias craniofaciais. Desta forma, verifica-se a necessidade de desenvolver treinamentos para preparar este professor. Independentemente da diversidade do público encontrado em sala de aula é primordial o desenvolvimento do processo ensinoaprendizagem com sucesso, considerando os princípios de igualdade e equidade tal como previsto por lei. Portanto, este estudo pretendeu acender uma discussão sobre o sistema educacional inclusivo e a importância da formação adequada dos professores para atuarem com esses alunos, considerando que haja a oportunidade, de forma igualitária, para todos os alunos inseridos no sistema de ensino.

A necessidade da formação continuada do professor do ensino fundamental tem sido insistentemente debatida em contextos educacionais e literários, vinculados aos aspectos prático-administrativos e motivacionais. E quando se trata do conhecimento mais específico, como no caso das anomalias craniofaciais, o domínio é reconhecidamente insipiente, conforme evidenciado no presente estudo. Desta forma, uma das limitações identificadas foi relacionada à amostra restrita, justificada pela adesão dos participantes na pesquisa, no período proposto, cujo número amostral mais robusto possibilitaria maior amplitude na generalização dos achados.

As considerações aqui fundamentadas tiveram o propósito de contribuir para reflexões que impulsionem os educadores às atitudes proativas, na busca constante do conhecimento e da melhoria na qualidade de suas práticas pedagógicas, adequando técnicas de ensino e material didático, ao efetivo aprendizado acadêmico dos alunos.

\section{REFERÊNCIAS}

AQUINO, S. N. et al. Study of patients with cleft lip and palate with consanguineous parents. Braz J Otorhinolaryngol, v. 77, n. 1, p. 19-23, 2011. Disponível em: http://www.scielo.br/pdf/bjorl/v77n1/en_v77n1 a04.pdf. Acesso em: 10 out. 2017.

ARAÚJO, A. P. Q. C. Avaliação e manejo da criança com dificuldade escolar e distúrbio de atenção. Jornal de Pediatria, Rio de Janeiro, v. 78, n. 1, p. 
104-110, 2002. Disponível em: http://www.jped.com.br/conteudo/02-78-

s104/port.pdf. Acesso em: 29 set. 2017. https://doi.org/10.1590/S0021-

\section{3}

BEE, H.; BOYD, D. A criança em desenvolvimento. 12. ed. Porto Alegre: Artmed, 2011.

BERNARDINO, L. A contribuição da Psicanálise para a atuação no campo da educação especial. Estilos da Clínica, v.12, n. 22, pp. 48-67, 2007. Disponível em: http://pepsic.bvsalud.org/pdf/estic/v12n22/v12n 22a04.pdf. Acesso em: 05 jan. 2017.

BROWN, T.E. Transtorno de déficit de atenção: a mente desfocada em crianças e adultos. Porto Alegre: Artmed, 2007.

CAMINHA, M.I. Fissuras e cicatrizes familiares: dinâmica relacional e a rede social significativa de famílias com Crianças com fissura labiopalatal. 2008. 255 f. Dissertação (Mestrado em Psicologia) - Universidade Federal de Santa Catarina, Florianópolis, 2008. Disponível em: https://repositorio.ufsc.br/bitstream/handle/123 456789/91669/258202.pdf?sequence=1\&isAllow ed=y. Acesso em: 07 jan. 2017.

CAPELOZZA FILHO, L.; SILVA FILHO, O. G. S. Fissuras Lábio - palatais - Considerações Epidemiológicas. In: PETRELLI, E. Ortodontia para fonoaudiologia. São Paulo: Lovise, 1994. p.197238.

CARVALHO F.B.; CRENITTE, P.A.P.; CIASCA, S. M. Distúrbios de aprendizagem na visão do professor. Rev. Psicopedagogia, v. 24, n. 75, p.229-239, 2007. Disponível em: http://pepsic.bvsalud.org/pdf/psicoped/v24n75/ v24n75a03.pdf. Acesso em: 10 out. 2017.

CIASCA, S. M.; RODRIGUES S. D.; SALGADO C. A. TDHA-Transtorno de Déficit de Atenção e Hiperatividade. Rio de Janeiro: Revinter, 2010. p. 194.

DOMINGUES, A.B.C.; PICOLINI, M. M.; LAURIS, J. R.; MAXIMINO, L. P. Desempenho escolar de alunos com fissura labiopalatina no julgamento de seus professores. Rev. Soc. Bras. Fonoaudiologia, v. 16, n. 3, p. 310-316, 2011. Disponível http://www.scielo.br/pdf/rsbf/v16n3/12.pdf.

Acesso em: 29 set. 2017.

https://doi.org/10.1590/S1516-

80342011000300012

FERRO, M. R.; MORETTI, C. N.; TABAQUIM, M. D. L. M. Remediação neuropsicológica das funções executivas de sujeito com del 22q11. 2 e fissura submucosa. In: CURSO DE ANOMALIAS CONGÊNITAS LABIOPALATINAS, 46., 2013, Bauru. Anais [...]. Bauru: Hospital de Reabilitação de Anomalias Craniofaciais, 2013.

GANNAM, L. M.; TEIXEIRA, M. F.; TABAQUIM, M. L. M. Função atencional e flexibilidade cognitiva em escolares com fissura labiopalatina, São Paulo, Rev. Psic. da Educação, n. 40, p. 87-101, $2015 . \quad$ Disponível em: http://pepsic.bvsalud.org/pdf/psie/n40/n40a07.p df. Acesso em: 30 set. 2017.

GLAT, R.; PLETSCH, M. D. O papel da Universidade no contexto da política de educação inclusiva: reflexões sobre a formação de recursos humanos e a produção de conhecimento. Revista Educação Especial, Santa Maria, v. 23, n. 38, p. 345-356, $2010 . \quad$ Disponível em: https://periodicos.ufsm.br/educacaoespecial/arti cle/view/2095/1444. Acesso em 24 set. 2017.

HOLANDA, E.R.; COLLET, N. Escolarização da criança hospitalizada sob a ótica da família. Texto Contexto Enfermagem, Florianópolis, v. 21, n. 1, p. 34-42, 2012. Disponível em: http://www.scielo.br/pdf/tce/v21n1/a04v21n1.p df. Acesso em: 20 jan. 2017. https://doi.org/10.1590/S010407072012000100004

JACOB, M. F.; TABAQUIM, M. L. M. Atenção e linguagem em crianças com fissura labiopalatina. Rev. Saúde e Desenvolvimento Humano, Bauru, v. 2, n. 1, p. 15-27, 2014. Disponível em: http://www.revistas.unilasalle.edu.br/index.php/ saude_desenvolvimento/article/view/1314/109. Acesso em: 30 set. 2017.

JOAQUIM, R.; TABAQUIM, M.L.M. Avaliação Neuropsicológica de Crianças com Fissura Labiopalatina. Arch Health Invest, Bauru, v.2, n.5, p.59-67, 2013. Disponível em: http://www.archhealthinvestigation.com.br/ArcH I/article/view/214/469. Acesso em: 30 mar. 2017. 
KOTULAK, R. Inside the brain: Revolutionary discoveries of how the mind works. Kansas City: Andrews McMeel Publishing, 1997. Cap. 2. https://doi.org/10.1006/pmed.1998.0281

LADEWIG, I. A importância da atenção na aprendizagem de habilidades motoras. Rev. Paul. Educ. Fís., São Paulo, supl. 3, p. 62-71, 2000. Disponível em: http://citrus.uspnet.usp.br/eef/uploads/arquivo/ v14\%20supl3\%20artigo7.pdf. Acesso em: 30 jan. 2017.

LEWIS, M. Tratado de psiquiatria da infância e adolescência. Porto Alegre: Artes Médicas, 1995. Cap. 7.

LURIA, A. R. Fundamentos de neuropsicologia. São Paulo: EDUSP, 1981.

MONDELLI, M. F. C. G.; VENTURA, L. M. P.; FENIMAN, M. R. Ocorrência de perda auditiva unilateral em pacientes com fissura labiopalatina. Revista CEFAC, Bauru, v. 15, n. 6, p. 1441-1446, $2013 . \quad$ Disponível em: http://www.scielo.br/pdf/rcefac/v15n6/v15n6a0 6.pdf. Acesso em: 30 set. 2017. https://doi.org/10.1590/S1516-

$\underline{18462013000600006}$

NAGEM, F. H.; MORAES, N.; ROCHA, R. G. F. Contribuições para o estudo da prevalência das malformações congênitas labiopalatinas na população escolar de Bauru. Rev. Fac. Odontologia, São Paulo, v.2, p. 111-128, 1968. Disponível em: http://hrac.usp.br/wpcontent/uploads/2015/10/nagem_etal_1968.pdf. Acesso em: 03 mar. 2017.

NIQUERITO, A. V.; TABAQUIM, M. L. M. Remediação neuropsicológica das funções atencionais em crianças com fissura labiopalatina. 2013. 117 f. Dissertação (Mestrado em Ciências da Reabilitação) - Hospital de Reabilitação de Anomalias Craniofaciais, Universidade de São Paulo, Bauru. Disponível em: http://www.teses.usp.br/teses/disponiveis/61/6 1132/tde-12112013-152229/pt-br.php. Acesso em: 03 mar. 2017.

OLIVER, K.A.; ANTONIUK, A.S.; BRUCK, I. Neurodesenvolvimento Infantil: definição e conceito. In: RIECHI, T. I. J. S.; VALIATI, M .R. M. S.; ANTONIUK, A. $\quad$ S. Práticas em
Neurodesenvolvimento Infantil: fundamentos e evidências científicas. Curitiba: Íthala, 2017. p. 23-31.

PALANDI, B.B.N.; GUEDES, Z.C.F. Aspectos da fala de indivíduos com fissura palatina e labial, corrigida em diferentes idades. Revista CEFAC, São Paulo, v. 13, n. 1, p. 8-16, 2011. Disponível em: http://www.scielo.br/pdf/rcefac/v13n1/7109.pdf. Acesso em: 30 set. 2017.

PAPALIA, D. E.; OLDS, S. W.; FELDMAN, R. D. Desenvolvimento Humano. 8. ed. Porto Alegre: Artmed, 2006. https://doi.org/10.1590/S151618462011005000012

POPI, J. M.; RIECHI, T. I. J. S. Avaliação cognitivocomportamental no Transtorno da Atenção. In: RIECHI, T. I. J. S.; VALIATI, M. R. M. S.; ANTONIUK, A. S. Práticas em neurodesenvolvimento infantil: fundamentos e evidências científicas. Curitiba: Íthala, 2017. p. 143-152.

PRUDENCIATTI, S.; PEREIRA, R. S.; TABAQUIM, M. L. M. Identificação das competências necessárias para a aprendizagem de leitura e escrita de crianças com fissura labiopalatinas: estudo comparativo. Rev. Psicopedagogia, Bauru, v. 33, n. 102, p. 262-271, 2016. Disponível em: http://pepsic.bvsalud.org/pdf/psicoped/v33n102 /05.pdf. Acesso em: 20 mar. 2017.

RÉ, A. H. N. Crescimento, maturação e desenvolvimento na infância e adolescência: Implicações para o esporte. Revista Motricidade, São Paulo, v. 7, n. 3, p. 55-67, 2011. Disponível em:

http://www.revistamotricidade.com/arquivo/201 1_vol7_n3/v7n3a08.pdf. Acesso em: 24 set. 2017. https://doi.org/10.6063/motricidade.7(3).103

SANT'ANA, I. M. Educação inclusiva: concepções de professores e diretores. Rev. Psicologia em Estudo, Maringá, v. 10, n. 2, p. 227-234, 2005. Disponível em: http://www.scielo.br/pdf/pe/v10n2/v10n2a09.p df. Acesso em: 13 out. 2017. https://doi.org/10.1590/S141373722005000200009

SENO, M. P. Transtorno do déficit de atenção e hiperatividade (TDAH): o que os educadores sabem? Rev. psicopedagogia, Marília, v. 27, n. 84, p. 334-343, 2010. Disponível em: 
http://pepsic.bvsalud.org/pdf/psicoped/v27n84/ v27n84a03.pdf. Acesso em: 12 out. 2017.

SILVA, A.P.M.; ARRUDA, A.L.M.M. O Papel do Professor Diante da Inclusão Escolar. Revista Eletrônica Saberes da Educação, v. 5, n. 1, p. 2539, 2014. Disponível em: http://docs.uninove.br/arte/fac/publicacoes_pdf /educacao/v5_n1_2014/Ana_Paula.pdf. Acesso em: 30 mar. 2017.

SILVA, C. M. et al. School in Health Promotion for children with cleft lips and palates. Text Context Nursing, Florianópolis, v. 22, n. 4, p. 1041-8, 2013. Disponível em: http://www.scielo.br/pdf/tce/v22n4/en_21.pdf. Acesso em 30 mar. 2017.

TABAQUIM, M. L. M. et al. Concepção de professores do ensino fundamental sobre a dislexia do desenvolvimento. Rev. Bras. Estud. Pedagog., Brasília, v. 97, n. 245, p. 131-146, 2016. Disponível em: http://www.scielo.br/pdf/rbeped/v97n245/21766681-rbeped-97-245-00131.pdf. Acesso em: 29 set. 2017. https://doi.org/10.1590/S2176$\underline{6681 / 368214020}$

TRINDADE, I. E. K.; SILVA FILHO, O. G. Fissuras Labiopalatinas: uma abordagem interdisciplinar. Bauru: Santos Editora, 2007.

TOVANI-PALONE, MR. Fonoaudiologia e fissuras labiopalatinas. Rev. Fac. Med., v.63, n. 4, pp. 7412, 2015. DOI: 10.15446/revfacmed.v63.n4.51710. Disponível em: https://revistas.unal.edu.co/index.php/revfacme d/article/view/51710. Acesso em: 10 fev. 2019. https://doi.org/10.15446/revfacmed.v63.n4.5171 $\underline{0}$

TOVANI-PALONE, MR, SALDIAS-VARGAS, VP. Factores genéticos $y$ fisuras orofaciales no sindrómicas. Rev Fac. Med., v.64, n. 2, pp.381-3, 2016. DOI: 10.15446/revfacmed.v64n2.53551. Disponível em: https://www.crossref.org/iPage?doi=10.15446\%2 Frevfacmed.v64n2.53551. Acesso em: $10 \mathrm{fev}$. 2019.

https://doi.org/10.15446/revfacmed.v64n2.5355 $\underline{1}$

TOVANI-PALONE, M. R.; FORMENTON, A.; BERTOLINI, S. R. Are There Regionalisation of
High Complexity Surgeries and Decentralisation of Outpatient Treatment Services for Cleft Lip and/or Palate in the State of São Paulo, Brazil? HK J Paediatr, v. 23, n. 3, p. 211-219, 2018. Disponível em: http://www.hkjpaed.org/details.asp?id=1184\&sh ow=1234. Acesso em: 10 fev. 2019.

Submetido: 23/01/2019

Correções obrigatórias: 08/02/2019

Aceite final: 21/03/2019 